\title{
Effectiveness of RajYoga Meditation in Education, Teaching, and Life
}

\author{
Shweta Choudhary \\ Mahaveer Ayurvedic Medical College and Hospital, Meerut, India; \\ Choudhary Charan Singh University Meerut (UP), Meerut, India
}

\begin{abstract}
Rajyoga can be defined in a number of ways. The word "yoga” simply means "union”, and the word "raja” means "Supreme”, "King”, or "Master”. Rajyoga is the king of all yogas, because through it, one can become sovereign. Not over others, because that would be artificial. The power that gain, is the power of control over own mind, because it is one's own mind that has been creating sorrow and distress. In spiritual terminology, “yoga” means communion of the self with the Supreme Being. Once, the communion is established the practitioner receives positive vibrations of tranquility, bliss, purity, mercy, from the Supreme Soul. God, the Supreme, always vibrating with the frequency of peace, bliss, purity, power, and all other positive qualities. Yoga is the link established by single minded, passionate, loveful, and purposeful intellectual remembrance of God which brings about the divinization of man, i.e., the purification of self, the conquest of vices, and the attainment of sublime peace and heavenly happiness. God radiates the seven rays (love, peace, happiness, bliss, power, knowledge, and purity) in whole universe, Earth's atmosphere (five elements: air, water, fire, earth, and sky). Nature is very sensitive to these vibrations and all of us are the part of nature, if we radiate these vibrations by rajyoga meditation to nature, surroundings. It will act as natural senatizer and also create a positive aura around us, because at the time of meditation, we catch these frequencies from the universe and heal ourselves and radiate in surrounding so that positive energy creates and destroy negative energy or can create paradise on this earth.
\end{abstract}

Keywords: rajyoga, happiness, life, better health

\section{The Body of Paper}

Rajyoga is the direct connection with our supreme father God. God is point of light. He lives in incorporeal world (Red golden Area beyond the physical world, substatle world), which is called "soul world", "sweet home", or "param dham". This is explained in different ways in different religion. He is the ocean of love, peace, happiness, bliss, knowledge, power, and purity. In original form, we are also point of light.

Our original home is "param dham". We came here to play a role. Life is the combination of soul and physical body. As we can see in this figure soul (point of light) situated between the fore head near peneal gland. Soul is also having these seven quality as our supreme father in original form but these qualities have been depleted due to five vices, for instance, lust, anger, ego, attachment, and jealous. And nature is very sensitive for these positive or negative vibrations. We can achieve our original identity by the practice of

Shweta Choudhary, Ph.D., AIIMS New Delhi, assistant professor, Mahaveer Ayurvedic Medical College and Hospital; Choudhary Charan Singh University Meerut (UP), Ministry of Health Ayush and CCIM. 
rajyoga meditation. Three quality has been found in soul-mind, body, and intellect. Soul act as computer oprater.

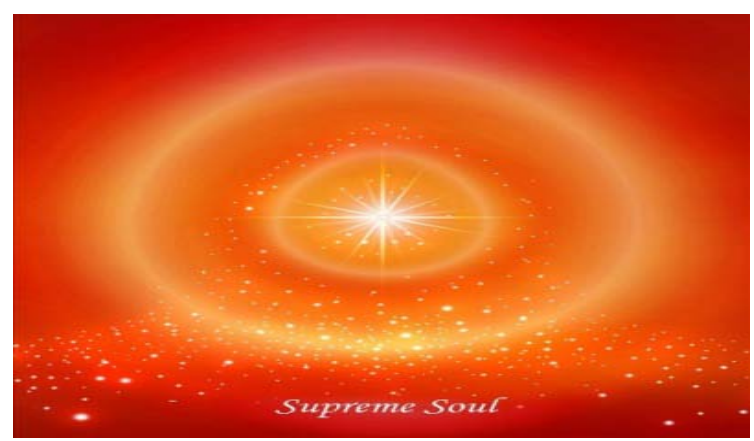

Figure 1. God in incorporeal world (Param dham).

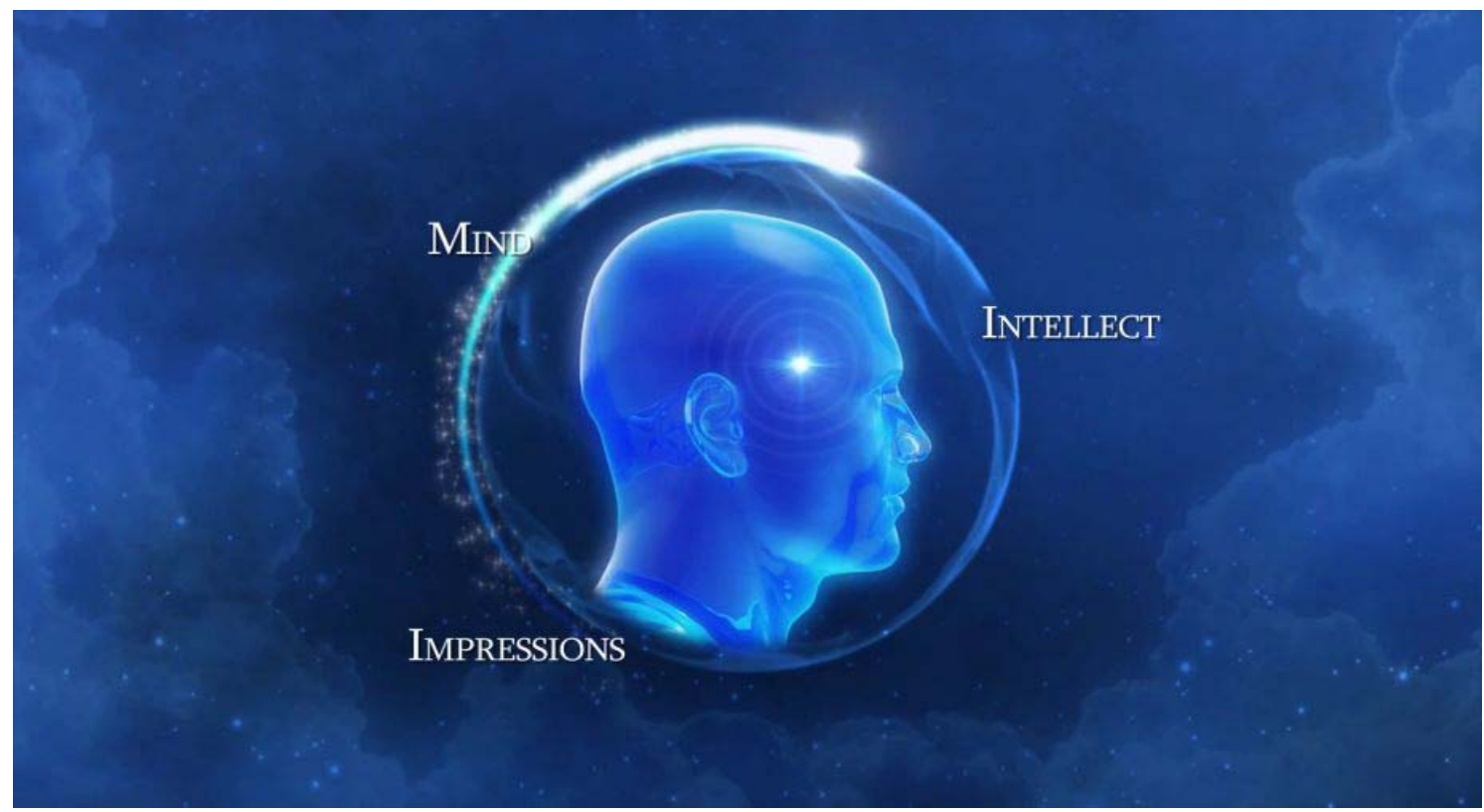

Figure 2. Soul (point of light) seat in for head. Mind, intellect, and impression three identity of soul just like an electron, proton, and neutron are the identities of atom.

We can consider relationship between soul and body as mobile sim (soul) or body (mobile) or as a driver (soul) and car (physical body). Life and death is a cycle as other natural cycle, i.e., transformation-delivery of soul (as seed) from a body. According to natural law, same seed form same species and for germination need of soil such as sprit need an embryo. As we know, in order to produce an ideal species, scientist need the best quality of seed by biotechnology, other things are base as a soil, $\mathrm{PH}$, and fertilizer, just like this, we also need spiritual biotechnology to refine our soul (human seed) to create an Ideal human race by rajyoga meditation. If we will change, world and nature change.

According to first law of thermodynamics, energy cannot be created or destroyed, so everything is cyclic in universe.

According to Brahma kumaris-nature complete its cycle in 5,000 years and the full life period of earth magnetic field is 5,000 years. Transformation of universe occurs in the end of cosmic cycle (time period 5,000 years). It is just like season repeat, this cycle also repeats every 5,000 years. It is divided in four eras: satug, 
treat, dwaper, and kallyug. Time period of each era is 1,250. Now, the time of camouflage age (time period 1936 to 2036). This is very important period in the end of Kallyug. In which transformation or Iron Age (kallyug) to Golden age Satyug by God Shiva. Reincarnation of god Shiva in the body of Brahma baba, first time in 1936 at Sindh hadrabad. Brahma baba was the founder of Brahma kumaris world Godly University and worked under the guidance of supreme father God Shiva (Point of light who lives in soul world or Paramdham). The mission of this institute to create paradise on earth by rajyoga meditation as we know when transformation occurs, there are many change happened in nature. Time is going on from darkness to lightness. Satyug and treta are also called "paradise", where always peace, love, healthy, or wealthiness was on earth. It is also mentioned in different religions. Because cycle is about to complete, Paradise will come on earth soon after transformation. We can reach there by learning rajyoga meditation for this we need to join brahma kumaris center nearby anywhere in world, can search on net.

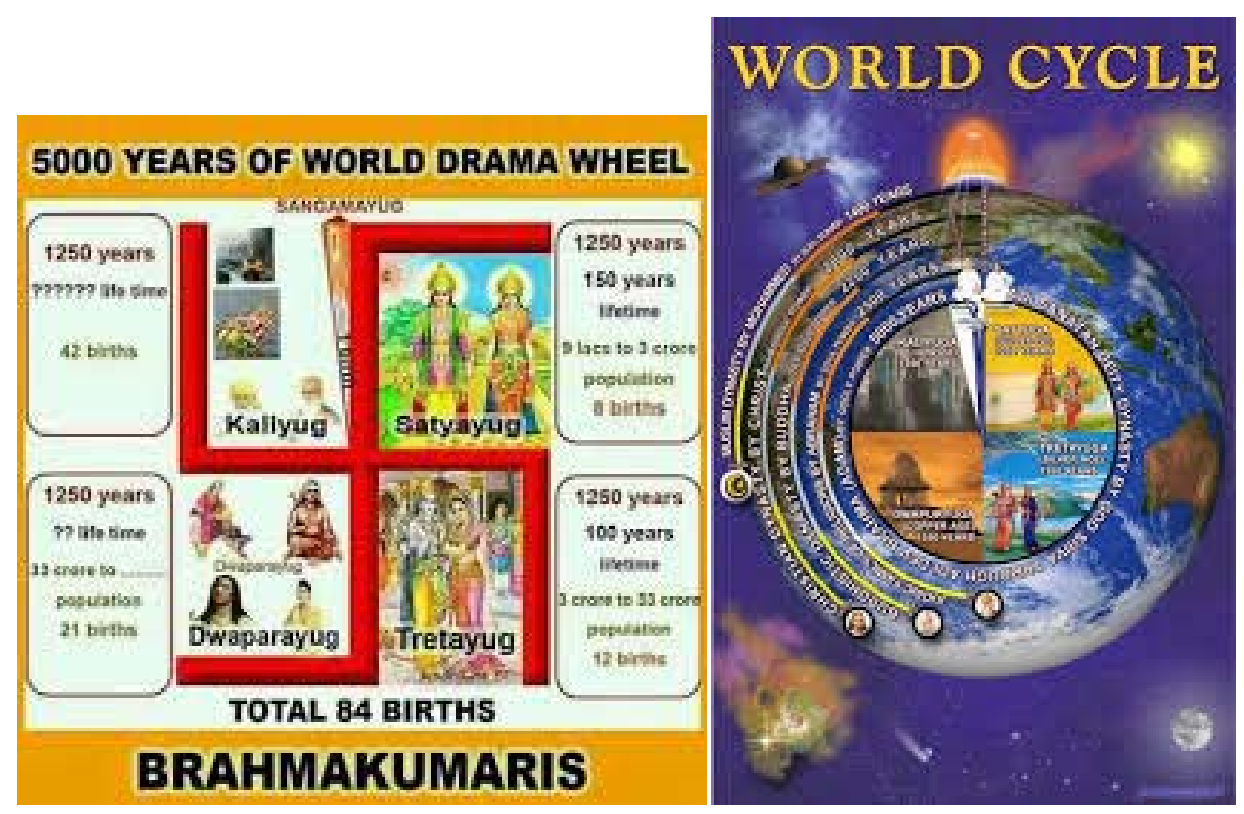

Figure 3. World (drama) cycle.

From above to below in universe-In top red orange area:

(a) Incorporeal world (soul world: Original home of soul);

(b) Subtle world (Angel's world): white lighted area beyond the stars or sky (perhaps our scientist did not reach there);

(c) Physical world-Where we live.

From camouflage age, we will reach back to sweet home after complete this cycle via subtle world (custom world), and then come again to Earth for playing our role according to time. Animals and other creatures section's are different in sweet home .We can come in Paradise (new world and golden era) by learning rajyoga meditation, so this time is very important.

Five basic lessons learnt during the course are: (a) the soul; (b) the supreme soul; (c) the law of karma; (d) the cycle; and (e) the tree of religions. 


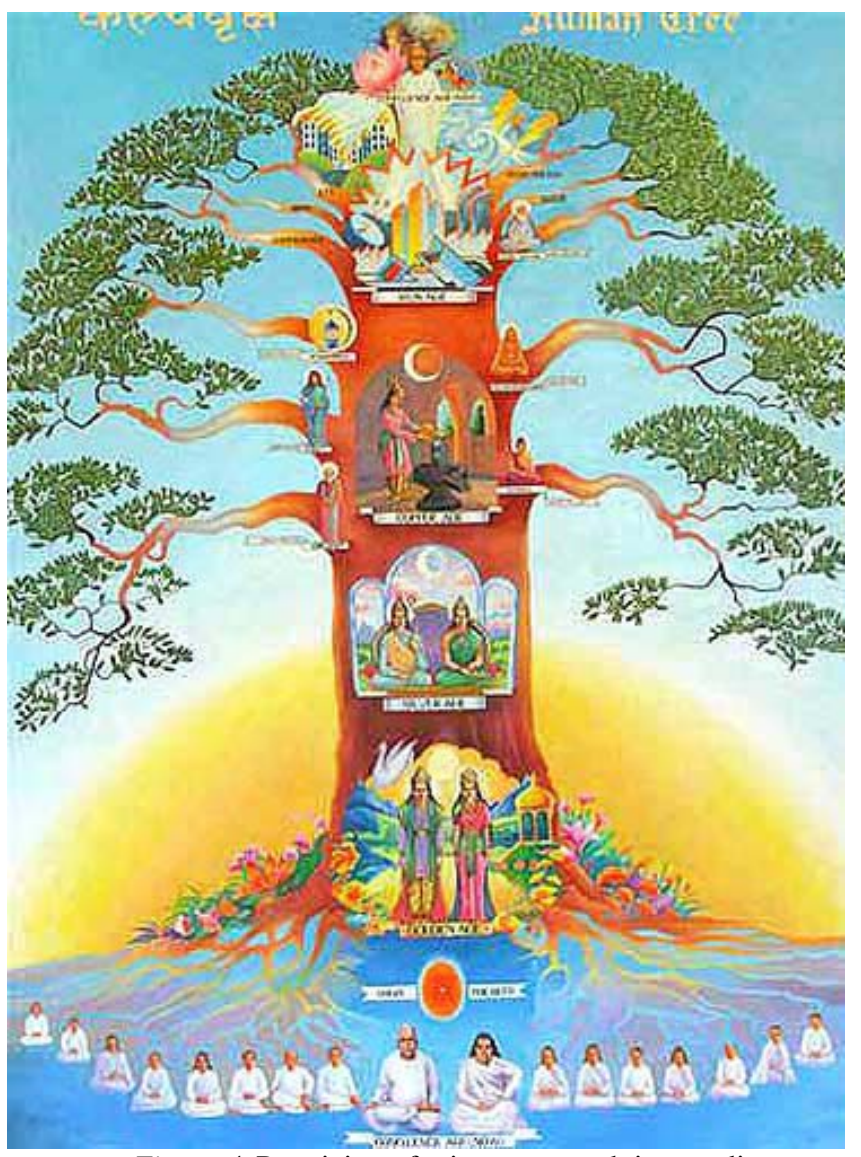

Figure 4. Practicing of rajyoga to reach in paradise. Spiritual trees

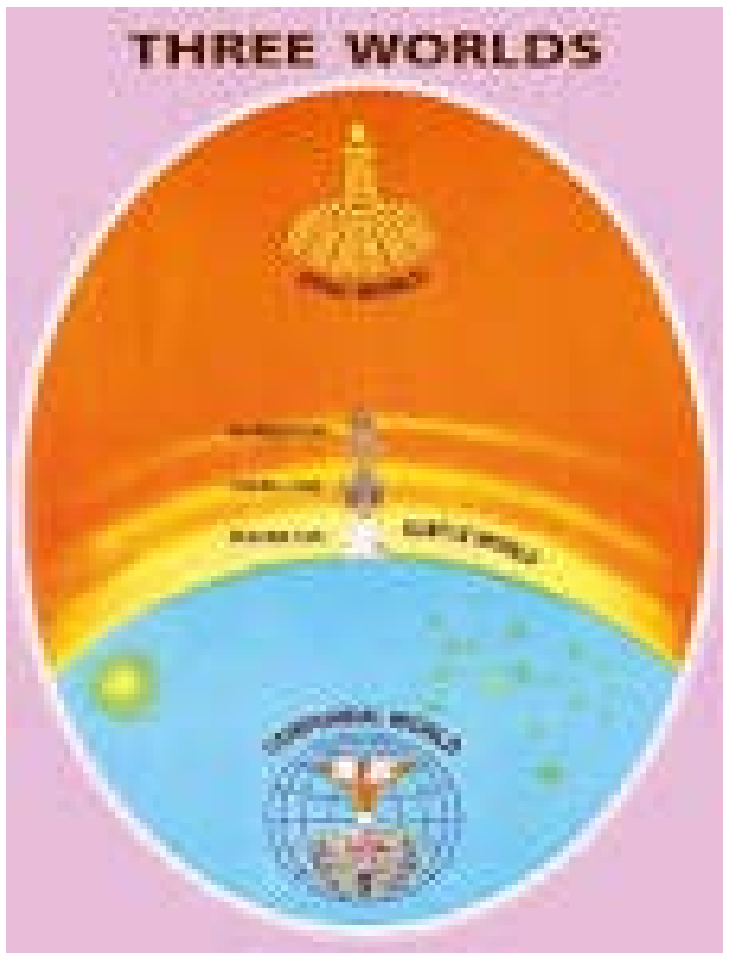

Figure 5. Three worlds in universe. 


\section{RajYoga Meditation in Education and Teaching}

Education is one such field where you cannot limit its scope and objectives within the fold of language. No doubt these goals would be specific, yet their attainment involves the whole human culture and civilization across the world.

Some of the specific objectives of the rajyoga meditation are:

1. To develop character in human personality with purity in consciousness, peace in mind and prosperity in life;

2. To re-establish through education and research, a society based on spiritual, moral, and human values;

3. To educate students to be free from bad habits, addictions, and blind faith and become the true and ideal support to their family and society;

4. To make the students aware of the threat of global warming and the importance of eco-friendly environment;

5. To improve the study and examination performance of students through concentration and memory power.

6. To develop harmony in relationships at family level and social level, so that we can create a one world family;

7. To develop and sustain the true art of living to lead a lotus-like life and have a balance of work and pleasure.

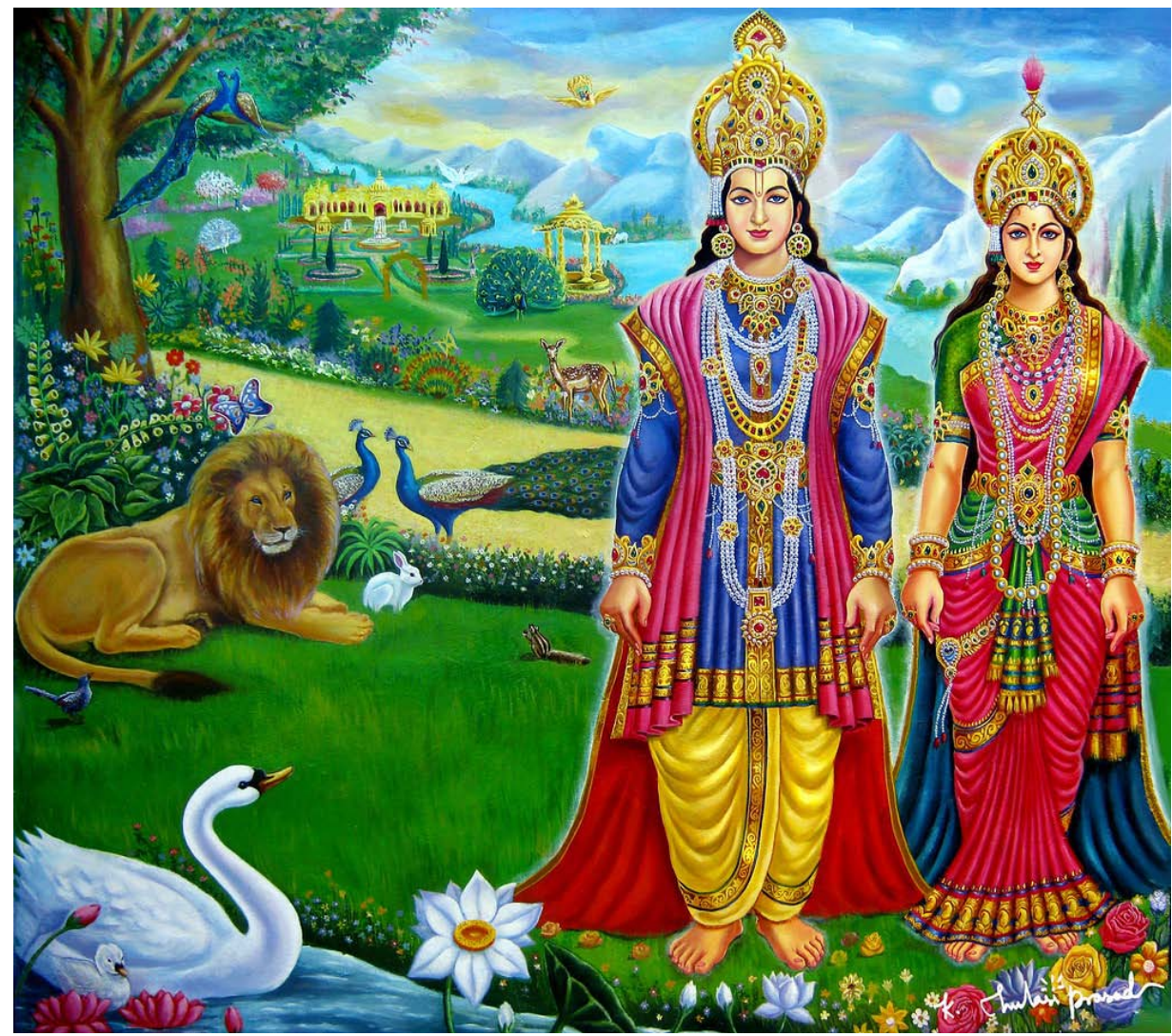

Figure 6. Divine personality by Rajyoga meditation. 


\section{RajYoga Meditation in Health}

Rajyoga meditation is a powerful tool for holistic healing. It has positive influence on the whole existence of human being. It harmonizes the physiological system as a whole as well as transforms all spheres of human existence-That is physical, mental, emotional, intellectual, occupational, social, and spiritual.

It also transforms one life style and relieves emotional and mental conflicts as well as brings lasting peace and satisfaction in one's life. One of the basic rules of holistic health care is healing takes place from within.

Rajyoga meditation is also a self initiated technique in which healing takes place as a result of activation of health promoting physiological and biochemical processes.

Rajyoga meditation practice potentiates the length, breadth, and depth of human existence. It is not a retreat from personal, social, and professional responsibility, but it is an art of fulfilling those responsibilities in a balanced way and achieving the goal of holistic self-development-physical, mental, intellectual, and spiritual.

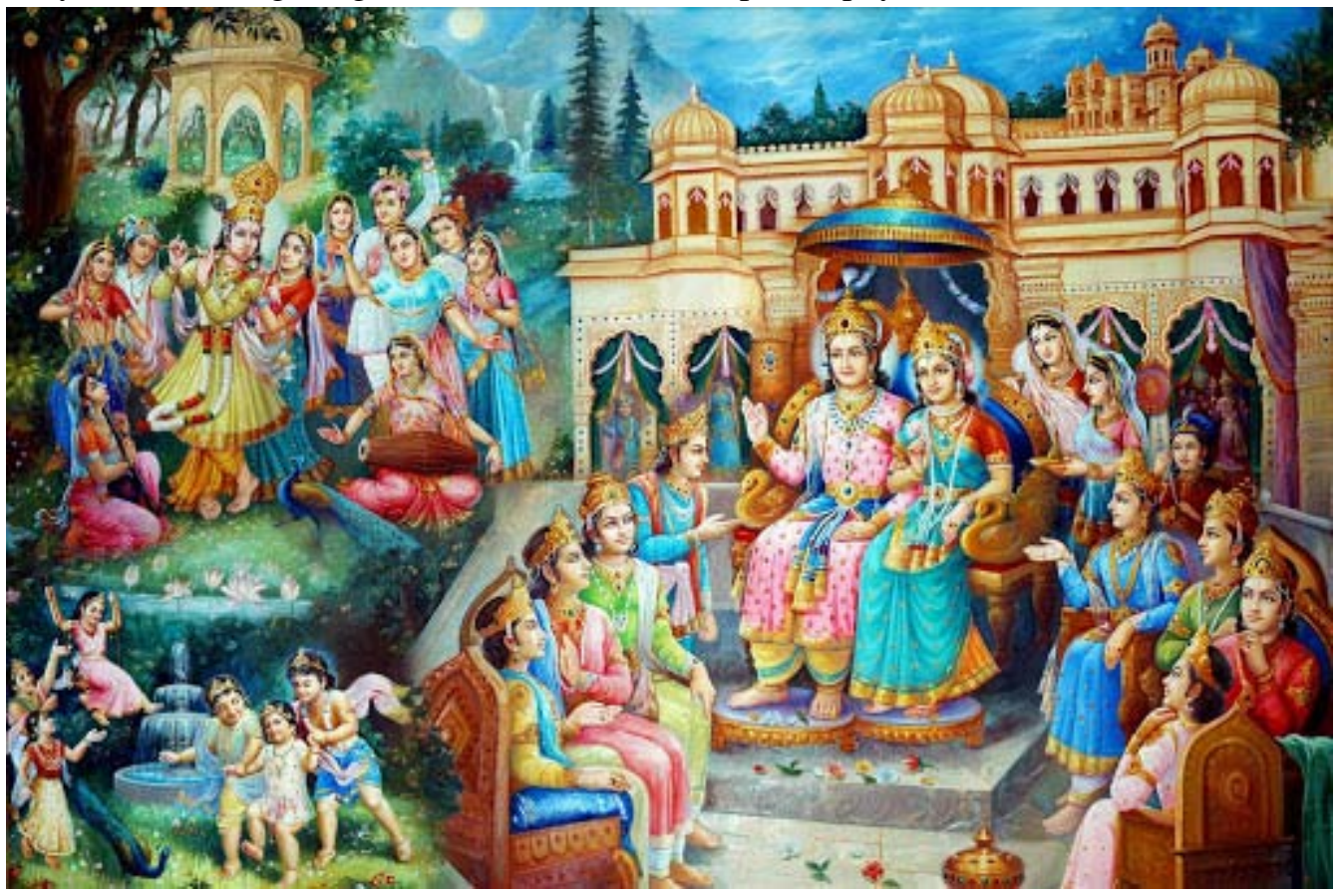

Figure 7. Paradise (Golden era, Satyug): This is about to come in near future.

\section{Effectiveness of RajYoga in Human Life}

Rajyoga improves the basic eight powers in human: (a) power to tolerate; (b) power to face; (c) power to pack up; (d) power to discriminate; (e) power to judge; (f) power to cooperate; (g) power to withdraw; and (h) power to accommodate.

Rajyoga improves seven basic qualities in human being: (a) peace; (b) love; (c) happiness; (d) bliss; (e) purity; (f) knowledge; and (g) power.

Rajyoga creates a very strong aura (energy field) around the body, so that any negative energy cannot enter in this area, i.e., natural vaccine and also radiate positive energy in atmosphere.

These eight powers improve our spiritual and mental power. 


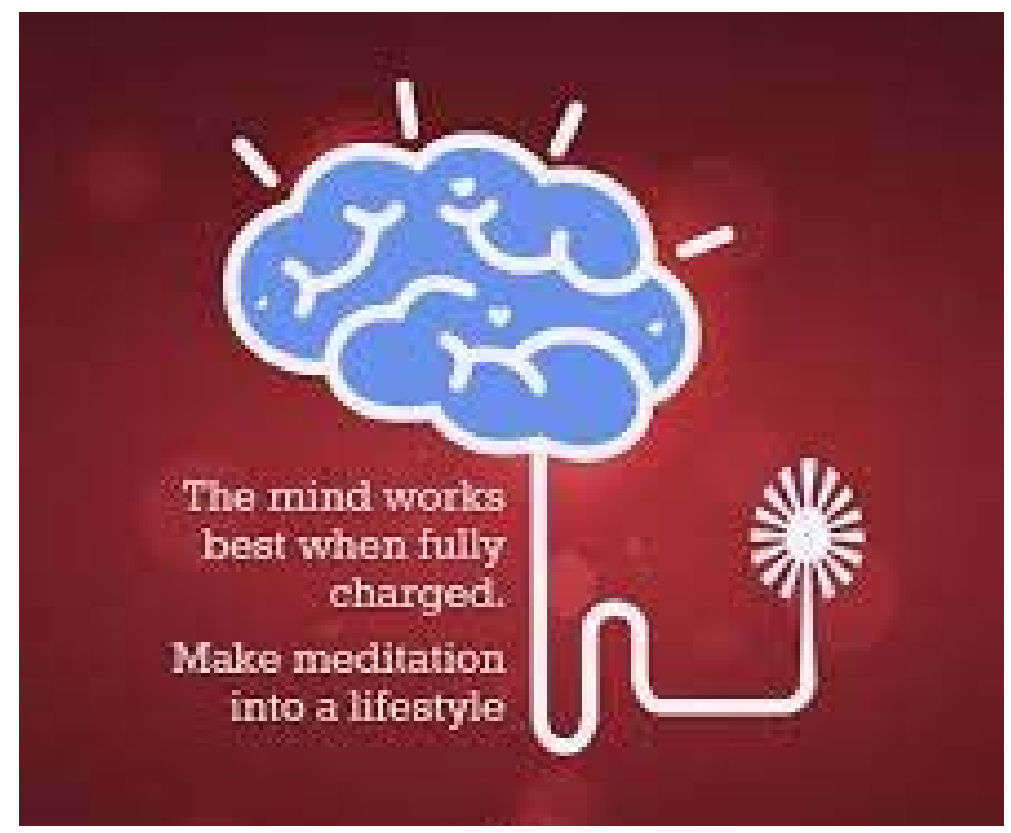

Figure 8. Effect of connection of soul with supreme soul.

\section{Conclusions}

Rajyoga meditation is one of the ancient solutions to modern problems. It has gained a lot of popularity around the world during the century. Rajyoga meditation, as many people often subscribe to, is not merely a method to attain mental peace, but also a powerful method to get rid of ignorance which causes various kinds of suffering in human life.

Rajyoga meditation provides peace of mind, relaxed body, positive attitude in every situation, improves concentration, increases clarity of thought, and develops the positive relationships, it realizes the purpose of life, feeling of content and stability and it provides good health, happiness, and prosperity in life.

Albert Enistein (Noble Prize Winner) said about God, who is invisible, has strong evidence just like we feel the smell of flower but could not visualize.

Invisible corona (can be seen only by electron microscope) can create disaster in this world thus invisible God (can see or visulise only by divine eyes) can create paradise on this Earth.

New York (USA) - An International Day of Yoga Committee at the United Nation (UN) yoga event was held at the prestigious Tiliman Chapel of the UN church center in the celebration of 5th Anniversary of International Yoga Day. For further inquiry can contact any Brahma Kumaris nearby. 

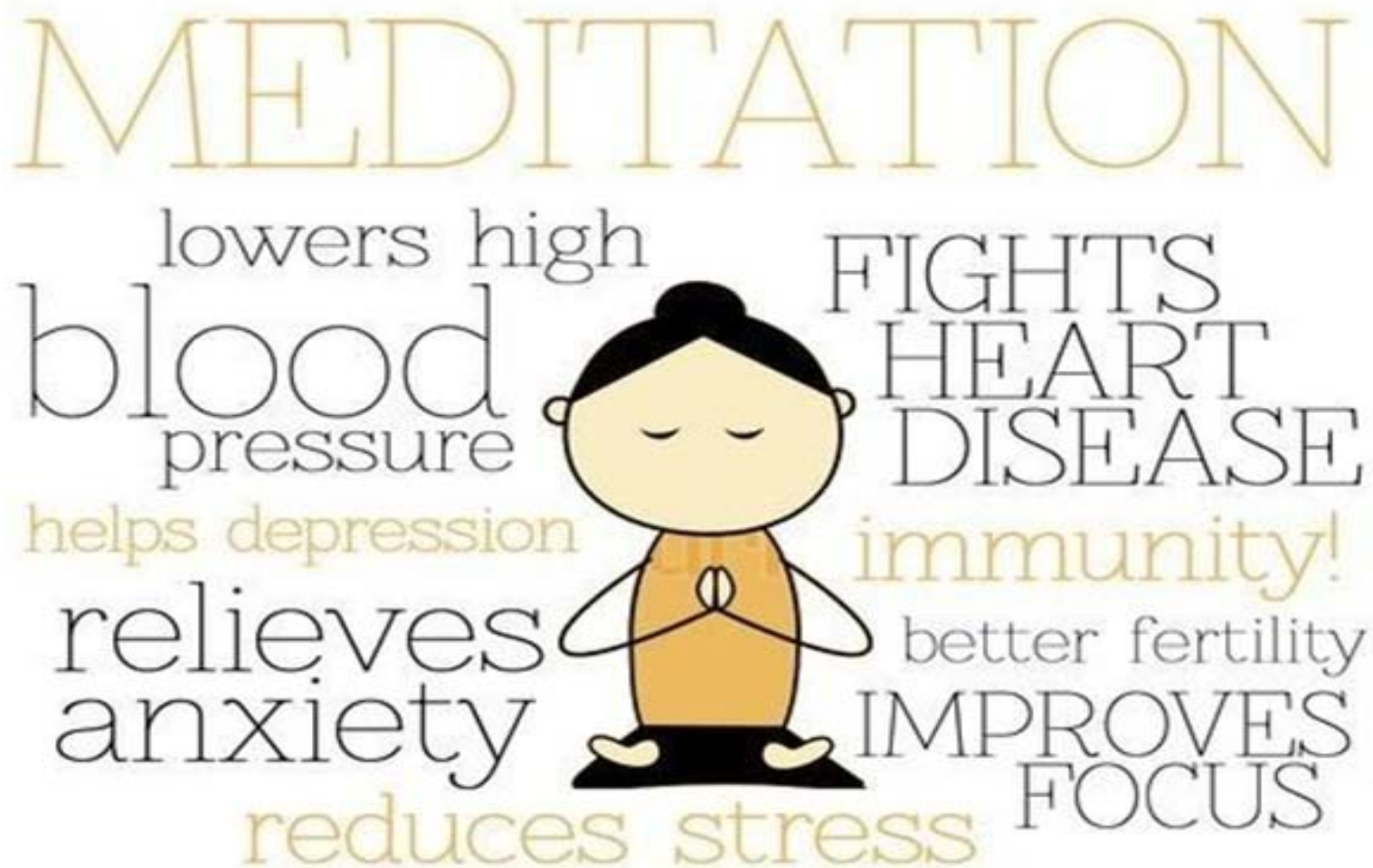

Figure 9. Effect of rajyoga meditation on health.

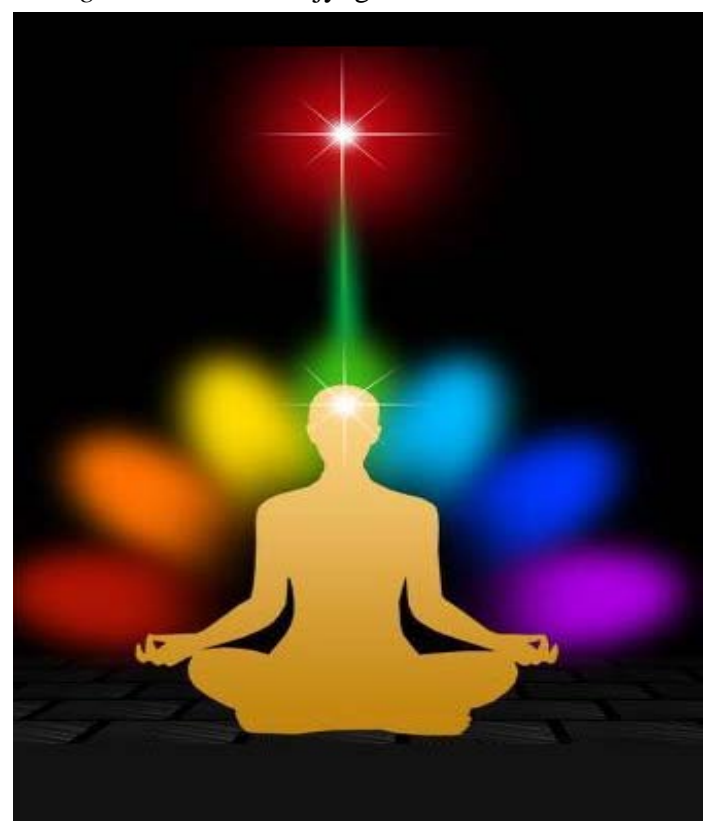

Figure 10. Energy radiation by rajyoga meditation. 


\section{ATTAINMENT OF 8 POWERS THROUGH RAJA YOGA}

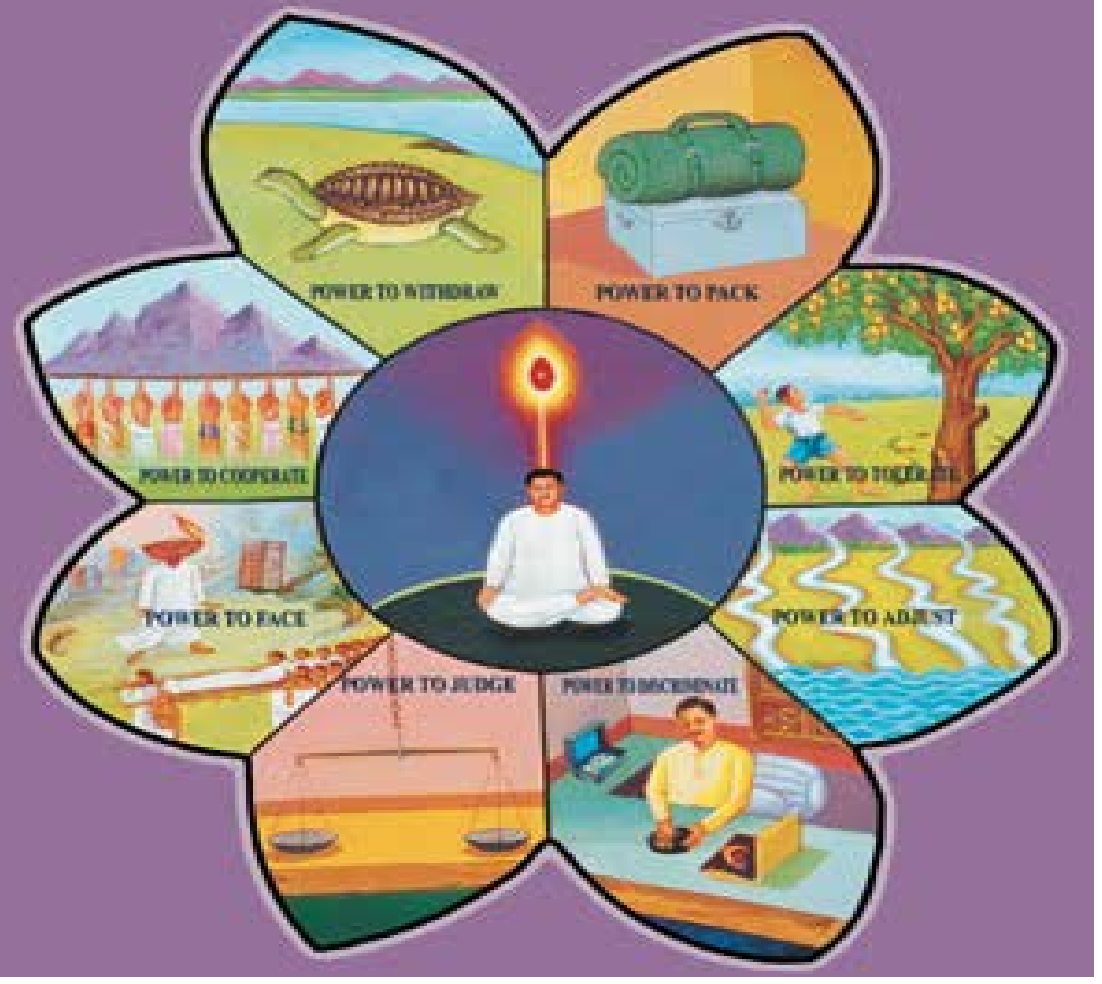

Figure 11. Development of 8 spiritual power by rajyoga meditation.

Center near by.

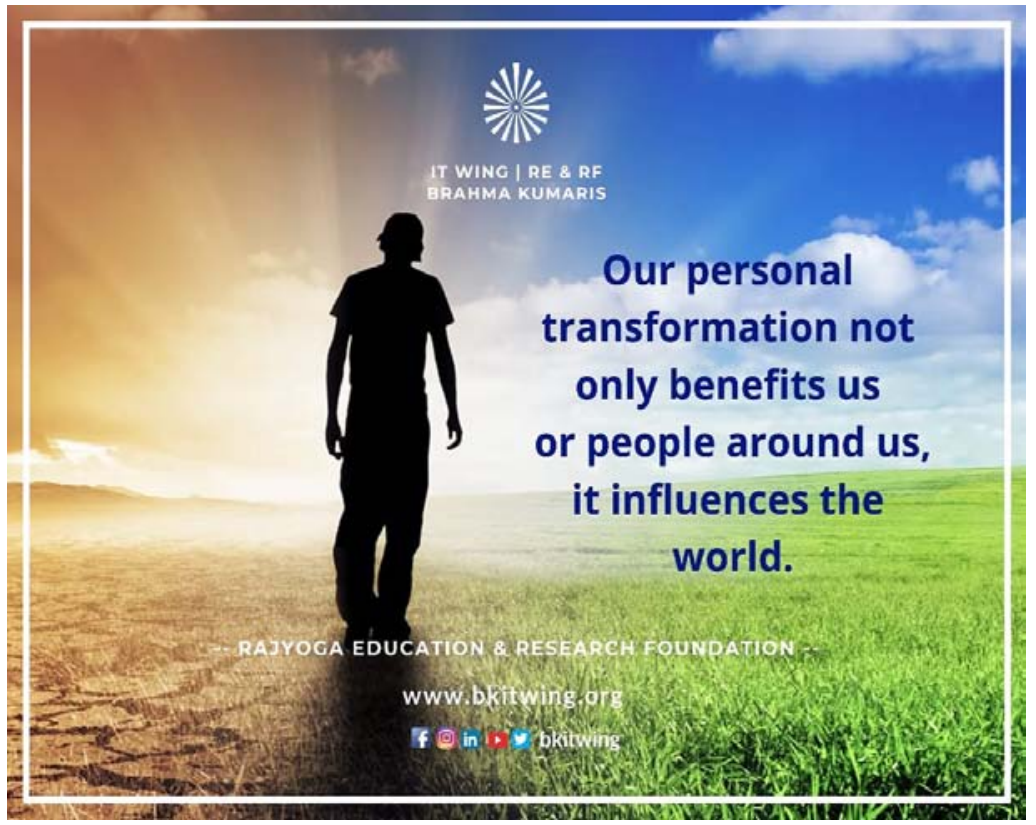

Figure 12. Effect of vibration in the world. 


\section{References}

Agrawal, J. L., Singh, A., \& Aggarwal, G. (2015). Effect of rajayoga meditation on blood pressure, heart rate, cardiac output, cardiac index, peripheral blood flow (right upper limb \& lower limb). International Journal of Physiology, 3(1), $151-156$.

Archana, M., Jyotsana, B., \& Mrunal, P. (2015, Jan.-Apr.). Effect of rajyoga meditation on the lipid profile of healthy adults in central India. Journal of Medical Sciences and Health, 1(1), 10-13.

Avdesh, S., Sachin, P., Partap, M., Banarsilal, S., \& Valsalan, N. (2015, November). Study on the effect of rajyoga lifestyle on deaddiction in India. Indian Journal of Private Psychiatry, 9(2), 35-39.

Dilip, V. K., \& Surekha, D. K. (2014). BK-rajajayoga-An evidence-based mental silence type of meditation. International Journal of Current Medical and Applied Sciences, 3(2), 20-28.

Gupta, M., Kumar, V., Agarwal, J. L., \& Jain, S. (2014). Effect of rajayoga meditation of brahma kumaris on pulmonary functions. International Journal of Physiology, 2(2), 22-25.

Jyotsana, R. B., Archana, D. M., Mrunal, S. P., \& Rajay, N. B. (2015). Autonomic functions in raja-yoga meditators. Indian Journal of Physiology and Pharmacology, 59(4), 396-340.

Kiran, Kawalinder K. G., Richa, G., \& Anterpreet, K. A. (2011, Sept.-Dec.). Influence of rajyoga meditation on cold press or response. International Journal of Basic and Applied Medical Sciences, 1(1), 139-143.

Komal, P., Biswas, D. A., \& Meshram, A. W. (2013). Modulation of anaerobic biomarker and lung functions by rajyoga meditation in young badminton players. International Journal of Medical Science and Public Health, 2(3), 664-669.

Maini, S., Kaur, H., \& Kohli, P. G. (2014, July). Effect of rajyoga meditation on serum cholesterol and HDL. International Journal of Medical and Dental Sciences, 3(2), 490-496.

Maini, S., Kaur, H., \& Maini, N. (2011, December). Effect of rajyoga meditation on the heart rate, blood pressure and ECG. Journal of Clinical and Diagnostic Research, 5(8), 1519-1522.

Neelam, D. S., \& Mrunal, S. P. (2012, Oct.-Dec.). Effect of short-term and long-term brahma kumaris rajyoga meditation on physiological variables. Indian Journal of Physiology and Pharmacology, 56(4), 388-392.

Nikhil, P., \& Barbara, G. (2005). Meditation in a lived faith context as therapeutic intervention for substance abuse, dependence and addiction: An empirical study. Archives of Indian Psychiatry, 7(1), 52-56.

Nishi, M., Arunima, G., Sarika, A, \& Om, P. (2013, February). Effect of raj yoga meditation on affective \& cognitive functions. International Journal of Health Sciences \& Research, 3(2), 38-46.

Ramesh, M. G., Sathian, B., Sinu, E., \& Kiranmai, S. R. (2013, October). Efficacy of rajayoga meditation on positive thinking: An index for self-satisfaction and happiness in life. Journal of Clinical and Diagnostic Research, 7(10), 2265-2267.

Rashmi, V., Kanti, V. R., \& Nirupama, D. (2008, Oct.-Dec.). Effect of rajyoga meditation on the lipid profile of post-menopausal women. Indian Journal of Physiology and Pharmacology, 52(4), 420-424.

Rashmi, V., \& Nirupama, D. (2002, November). Effect of meditation on respiratory system, cardiovascular system and lipid profile. Indian Journal of Physiology and Pharmacology, 46(4), 487-491.

Satish, K. G., Ramesh, C. S., Lajpat R., Chavan, V. D., Sameer D., Ramesh, C., Arora, W., Selvamurthy, H. K. C., \& Navin, C. N. (2011). Regression of coronary atherosclerosis through healthy lifestyle in coronary artery disease patients-Mount Abu Open Heart Trial (MAOHT). Indian Heart Journal, 63, 461-469.

Shirley, T., \& Desiraju, T. (1993). Autonomic changes in brahma kumaris rajyoga meditation. International Journal of Psychophysiology 15, 147-152.

Sukhsohale, N. D., Phatak, M. S., Sukhsohale, S. D., \& Agrawal, S. B. (2012). Does rajyoga meditation bring out physiological and psychological general well being among practitioners of it? International Journal of Collaborative Research on Internal Medicine \& Public Health, 4(12), 2000-2012.

Surekha, D. K., \& Dilip, V. K. (2013). Meditation (dhyan) versus relaxation: A review with comprehensive bibliography. International Journal of Basic and Applied Physiology, 2(1), 240-257.

Telles, S., \& Naveen, K. V. (2004, April). Changes in middle latency auditory evoked potentials during meditation. Psychological Reports, 94(2), 398-400.

Usha, K., Behrai, M., Venugopal, P., Vivekanandhan, S., \& Pandey, R. M. (2005). The effect of autogenic relaxation on chronic tension headache and in modulating cortisol response. Indian Journal of Anesthesia, 49(6), 474-478.

Usha, K., M. D. (2011, November). Effects of meditation on recovery after coronary artery bypass surgery. Journal of Preventive Cardiology, 1(2). 